\title{
Cox-maze precedure: evolution and clinical implications
}

\begin{abstract}
Atrial fibrillation is the most comon arrhythmia in worldwide. Stroke risk in AF is 5-fold higher than sinus rhythm. The left atrial appendage is the most important source of atrial emboli. The standard surgical "cut-and-sew" Cox-maze III procedure is the golden choice for surgical treatment of any type of atrial fibrillation, with success rate higher than $90 \%$. A full bi-atrial lesion pattern must be performed in the Cox-maze procedure. Left atrial appendage removal is included in all Cox-maze procedure. Alternative energy sources emerged as alternative for simplyfing the original Cox-maze procedure. However, success rate has not been as effective as with the original Cox-maze III procedure. Pulmonary vein isolation alone is not enough to treat chronic or persistent atrial fibrillation. Thoracoscopic techniques as well as catheter-based techniques are not able to get complete success in cases of mitral valve disease and atrial fibrillation and must keep away from these pull of patients.
\end{abstract}

Volume 8 Issue 5 - 2017

\author{
Ovidio A Garcia Villarreal \\ Department of Cardiovascular Surgery, Hospital Zambrano \\ Hellion. Monterrey, Mexico
}

Correspondence: Ovidio A Garcia-Villarreal, Sierra Nayarita 143, Col,Virginia Tafich, 66374, Santa Catarina, Nuevo León, Mexico,Email ovidiocardiotor@gmail.com

Received: April 17, 2017| Published: April 26, 2017

\section{Introduction}

Atrial fibrillation (AF) is a lethal disease killing by embolism or stroke. AF is responsible for $25 \%$ of all ischemic strokes. ${ }^{1}$ At the same time, these AF-related ischemic strokes are more lethal than other ethiology ischemic strokes. ${ }^{2}$ Patients with AF exhibit 5-fold stroke rate when comparing with those in normal sinus rhythm. ${ }^{3}$ Left atrial appendage (LAA) is the source of almost $90 \%$ atrial trombi. ${ }^{4}$ Indeed, LAA is removed in every Cox-maze procedure.

Actually, there is no offical data regarding to AF in patientes undergonig cardiac surgery in Mexico. In my experience, nearly 10\% of this pull of patients show AF at time of cardiac surgery. Moreover, $48 \%$ of cases with mitral valve (MV) disease have AF when cardiac surgery is indicated. At the same time, left atrial trombi is seen up to $40.7 \%$ in rheumatic $\mathrm{MV}$ disease and $\mathrm{AF}$, most of them arising from the LAA. ${ }^{5}$

The Cox-maze procedure was designed for treating any type of $\mathrm{AF}$ and atrial flutter. ${ }^{6}$ Since its creation and subsecuent modifications, this procedure has been the most effective method to eliminate AF. ${ }^{7}$ Success rate for Cox-maze procedure in eliminating AF is higher than $90 \%{ }^{8}$ The fisrt surgical procedure in a human being to treat AF was the atrial trans-section, which was carried out on October 13,1986 . However, this procedure was not fully successful because of AF recurrence as well as yatrogenic atrial flutter. This procedure evolved towards Cox-maze I on September 25, 1987. In February 1988, the second Cox-maze I procedure was performed. This second procedure was performed in the patient who initially underwent atrial trans- section in 1986. ${ }^{9}$ From 1987 to 1992 Prof. James Lewis Cox operated a series of 35 cases. Because of a cronotropic inability to exercise and delayed intra-atrial conduction, this one evolved to Coxmaze II in January 1992. Only 14 cases were performed from January to April 1992. However, this procedure was discontinued due to technical problems related to section and subsequent anastomosis of the superior vena cava. From 1992 on we began to use the Cox-maze III as we actually know it. $^{7}$

In addition to the design and application of the standard cut-andsew Cox-maze III, perhaps the most important Professor James L. Cox contribution has been the discovery and clinical application of the macro re-entrent circuits sustaining AF, which are larger than $5 \mathrm{~cm}$ in diameter. This is the basis of the design of the original Cox-maze III procedure. The last modification of the Cox-maze procedure known as Cox-maze IV has been created based on the replacement of surgical incisions by applying various alternative energy sources, usually radiofrequency and cryolesion. However, as simplification grows the success rate decreases. In fact, several authors have reported success rate of $50 \%$ at 5 -year follow-up. ${ }^{10}$

In surgical context, several energy sources has been described. Full transmurality and uniformity in ablation lines are a challenge when utilizing alternative energy sources. In fact, small isthmus of living tissue as $0.8 \mathrm{~mm}$ are enough to re-entrant mechanism in AF. ${ }^{11}$ While unipolar radiofrequency is unable in getting complete transmurality, bipolar radiofrequency is more likely to achieve this goal. Cryolesion is the most effective method to treat AF with alternative energy. ${ }^{12}$ Whatever the type of energy chosen, surgical "cut-and-sew" method remains as the gloden choice for surgically treating $\mathrm{AF} .{ }^{13}$

Several authors have stated paroxismal AF can be trated only by pulmonary vein isolation. This may be true only in $90 \%$ of cases, since $10 \%$ of ectopic firing sites are located outside de pumonary veins. However, once AF instaled, this arrhythmia is self-sustained by means of macro re-entrant circuits along both atria. ${ }^{14}$ Electrical remodeling in the whole atrial muscle is observed after 7days instaled. This is the reason why AF is called as "persistent" AF after the seventh day of released..$^{15}$ In this setting, pulmonary vein isolation alone is only effective in 30\%- $40 \%$ in eliminating AF. In cases of persistent or long-standing persistent AF, complete success is only possible by performig a bi-atrial pattern. ${ }^{14}$ Special emphasis must be placed on implications about a full bi-atrial incisions pattern in cases of mitral valve disease with chronic (persistent or long-standing persistent) AF. Simple pulmonary vein isolation is not enough to treat this type of chronic AF. ${ }^{16}$

Finally, more mini-invasive techniques, less effective outcomes. Thoracoscopic approach is not able to achieve all the full bi-atrial lesion pattern and it is very questionable whether this would benefit patients with mitral valve disease and concomitant $\mathrm{AF}{ }^{18}$

\section{Conclusion}

In conclusion, in the context of MV disease and chronic (persistent or long-standing persistent) AF, the only available and safe method to treat $\mathrm{AF}$ is the surgical "cut-and-sew" standard Cox-maze III 
procedure. Full bi-atrial lesion pattern is implicit in this concept. Alternative energy sources make easier the maze procedure but paying the price of less effectivness. PV isolation is not enough to eliminate other than paroxysmal AF. Catheter-based techniques must keep away from patients having MV disease and AF.

\section{Acknowledgments}

None.

\section{Conflicts of interest}

Author declares there are no conflicts of interest.

\section{Funding}

None.

\section{References}

1. Petersen P, Godtfredsen J. Risk factors for stroke in chronic atrial fibrillation. Eur Heart J. 1988;9(3):291-294

2. Fisher CM. Reducing risk of cerebral embolism. Geriatrics.

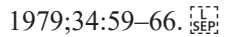

3. Benjamin E, Wolf P, Agostino R, et al. Impact of atrial fibrillation on the risk of death: the Framingham Heart Study. Circulation.

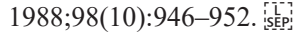

4. Blackshear L, Odell A. Appendage oblitaration to reduce stroke in cardiac surgical patients with atrial fibrillation. Ann Thorac Surg. 1996;61(2):755-759.

5. Garcia V, Heredia D. Left atrial appendage in rheumatic mitral valve disease: The main source of emboli in atrial fibrillation. Arch Cardiol Mex. 2016.

6. Cox J, Boineau J, Schuessler R, et al. Modification of the maze procedure for atrial flutter and atrial fibrillation. I. Rationale and surgical results. $J$ Thorac Cardiovasc Surg. 1995;110(2):473-484.
7. Cox J, Boineau J, Schuessler R, et al. Modification of the maze procedure for atrial flutter and atrial fibrillation. II. Surgical technique of the maze III procedure. J Thorac Cardiovasc Surg. 1995;110(2):485-95.

8. Garcia Villarreal. Cox-maze III procedure for atrial fibrillation. A preliminary study. Arch Cardiol Mex. 2016;86(3):208-213.

9. Cox JL. The first Maze procedure. J Thorac Cardiovasc Surg. 2011;141(5):1093-1097.

10. Stulak JM, Suri RM, Burkhart H, et al. Surgical ablation for atrial fibrillation for two decades: are the results of new techniques equivalent to the Cox maze III procedure? J Thorac Cardiovasc Surg. 2014; 147(5):1478-1486.

11. Thomas P, Wallace M, Ross L. The effect of a residual isthmus of surviving tissue on conduction after linear ablation in atrial myocardium. J Interv Card Electrophysiol. 2004;4(1):273-281.

12. Garcia OA. eComment. Alternative energy sources in surgery for atrial fibrillation. Interact Cardiovasc Thorac Surg. 2012;15(4):748-749.

13. Cox JL. The standard maze III procedure. Operative techniques in thoracic and cardiovascular surgery. 2000;5:2-22.

14. Cox JL. Atrial fibrillation I. A new classification system. J Thorac Cardiovasc Surg. 2003;126(6):1686-1692.

15. Kirchh P, Benussi S, Kotecha D, et al. ESC Guidelines for the management of atrial fibrillation developed in collaboration with EACTS Eur. J Cardiothorac Surg. 2016;50(5):e1-e88.

16. Garcia Villarreal OA. Pulmonary vein isolation for persistent atrial fibrillation. Long-term results. Asian Cardiovasc Thorac Ann. 2015;23(6):665-669.

17. Garcia OA. eComment. Pulmonary vein isolation is not enough to treat long-standing persistent atrial fibrillation. Interact Cardiovasc Thorac Surg. 2016;23(2):299.

18. Garcia Villarreal OA. eComment. Thoracoscopic maze: unresolved issues. Interact Cardiovasc Thorac Surg. 2016;22(6):768. 